\title{
Effect of the surface geology on strong ground motions due to the 2016 Central Tottori Earthquake, Japan
}

Takao Kagawa $^{1 *}$, Tatsuya Noguchi', Shohei Yoshida ${ }^{1}$ and Shinji Yamamoto ${ }^{2}$

\begin{abstract}
On October 21, 2016, an earthquake with Japan Meteorological Agency (JMA) magnitude 6.6 hit the central part of Tottori Prefecture, Japan. This paper demonstrates two notable effects of the surface geology on strong ground motions due to the earthquake. One is a predominant period issue observed over a large area. A seismic intensity of 6 lower on the JMA scale was registered at three sites in the disaster area. However, the peak ground acceleration ranged from 0.3 to $1.4 \mathrm{G}$ at the three sites because of the varying peak periods of observed strong ground motions. The spectral properties of the observations also reflect the damage around the sites. Three-component microtremors were observed in the area; the predominant ground period distributions based on horizontal to vertical spectral ratios were provided by the authors. The peak periods of the strong motion records agree well with predominant periods estimated from microtremor observations at a rather hard site; however, the predominant periods of the microtremors are slightly shorter than those of the main shock at the other two soft sites. We checked the nonlinear effect at the sites by comparing the site responses to small events and the main shock. The peak periods of the main shock were longer than those of the weak motions at the sites. This phenomenon indicates a nonlinear site effect due to large ground motions caused by the main shock. A horizontal component of the accelerogram showed rather pulsating swings that indicate cyclic mobility behavior, especially at a site close to a pond shore; ground subsidence of $\sim 20 \mathrm{~cm}$ was observed around the site. The peak periods of weak motions agree well with those of the microtremor observations. This implies an important issue that the predominant periods estimated by microtremors are not sufficient to estimate the effect of surface geology for disaster mitigation. We have to estimate the predominant periods under large ground motions considering the nonlinear site response of soft sediment sites.
\end{abstract}

Keywords: Strong ground motion, Ground predominant period, Microtremor observation, H/N spectrum, Nonlinear effect

\section{Introduction}

An earthquake with Japan Meteorological Agency (JMA) magnitude 6.6 occurred in the central part of the Tottori Prefecture, Japan, at 14:07 JST on October 21, 2016 (e.g., Earthquake Research Committee 2016). A JMA seismic intensity 6 lower with large peak ground acceleration (PGA) of $\sim 1.4 \mathrm{G}$ was observed at the Kurayoshi City Office Site (NIED 2016) close to the hypocenter at

\footnotetext{
*Correspondence: kagawa@cv.tottori-u.ac.jp

${ }^{1}$ Graduate School of Engineering, Tottori University, 4-101

Koyamacho-Minami, Tottori, Japan

Full list of author information is available at the end of the article
}

the foot of the mountain. The observation site is maintained by the National Research Institute for Earth Science and Disaster Resilience (NIED) as one of the K-NET stations installed throughout Japan (Aoi et al. 2004). Structural damages such as falling ridge roof tiles, crashing clay walls, and tumbling tombstones were widely observed around the site; however, complete collapses of buildings or houses were not reported in the area. On the contrary, there were other areas in which clusters of wooden houses collapsed completely. These areas are far away from the hypocenter and estimated fault plane (right bottom panel in Fig. 1; GSI 2016). Strong ground motions with JMA seismic intensities of 6 lower and 5 
upper were observed near the damaged areas, the Hojo and Daiei branches of Hokuei town office maintained by the local government (Nishimae 2004). However, the PGAs at the sites were $\sim 0.3$ and $0.6 \mathrm{G}$, respectively, remarkably smaller than the PGA at the Kurayoshi Site without severe damages.

The authors conducted microtremor observations in the damaged area and evaluated the predominant period of the ground surface (Noguchi and Kagawa 2014) based on horizontal to vertical (H/V) spectral ratios. Figure 1 shows the distribution of the predominant period and locations of the observation sites mentioned in this study. First, the spectral properties of the observed strong ground motions are considered, referring to the predominant period distribution map in the area with respect to the effect of surface geology.

Another key issue observed during the earthquake is the nonlinear site response of soft ground sites, especially the Togo Site, which is located in a reclaimed area close to a pond shore; an anomalous accelerogram was obtained from there, showing pulsating swings and cyclic mobility behavior (e.g., Iai et al. 1995). The peak periods of the main shock, longer compared with those of small events, suggest nonlinear site response at this site.
The same phenomenon was observed at the Hojo Site at which a JMA intensity of 6 lower was observed. The peak periods from strong ground motions at the two sites did not agree well with predominant periods obtained from preliminary microtremor observations. The second objective of this study is to evaluate the effect of the surface geology on strong ground motions at soft sedimentary sites.

\section{Effect of surface geology on observed main shock records}

The 2016 Central Tottori Earthquake was characterized by widely radiated ground motion from the source fault; most of the population of Southwest Japan felt the tremor. The observed maximum JMA seismic intensity due to the earthquake was 6 lower, compared with a modified Mercalli intensity of $\sim$ VIII. Table 1 shows basic information about the observation sites and characteristic values of strong ground motions caused by the earthquake. The sites are indicated in Fig. 1. The damage included the collapse of wooden houses, concentrated around the Hojo and Daiei sites.

Based on Table 1, the JMA seismic intensity of 6 lower was observed at the following sites: Kurayoshi City Office,

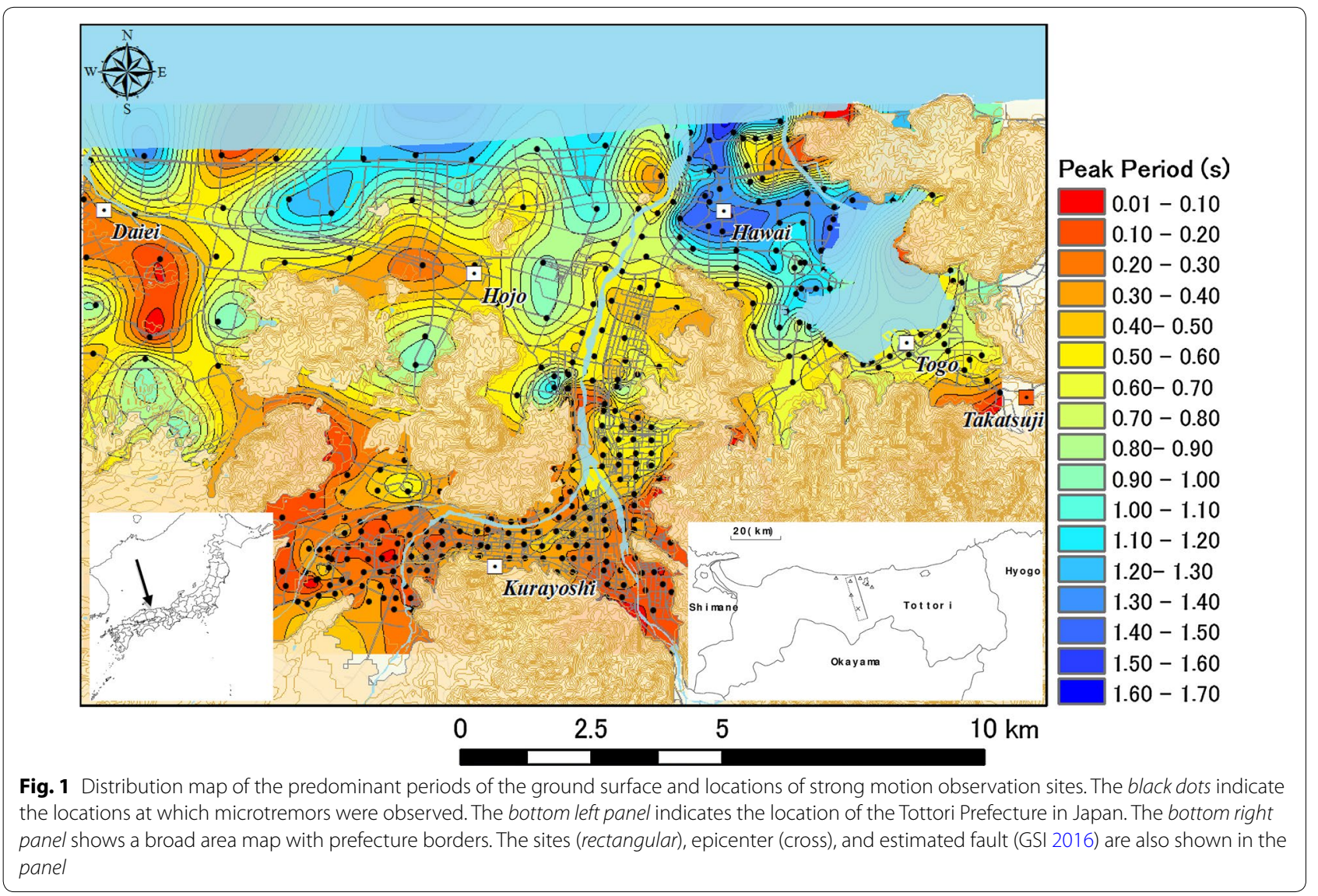


Table 1 Site information and characteristic values of the main shock

\begin{tabular}{|c|c|c|c|c|c|c|}
\hline Site name & Alias name & Operator & Latitude & Longitude & JMA intensity & PGA (Gal) \\
\hline Kurayoshi City Office & K-NETTTR005 & NIED & N35.4290 & E133.8253 & 6 lower (5.8) & 1381 \\
\hline Togo Branch & Ryuto, Yurihama Town & Tottori Pref. & N35.4674 & E133.8962 & 6 lower (5.8) & 565 \\
\hline Hawaii Branch & Hisadome, Yurihama Town & Tottori Pref. & N35.4901 & E133.8647 & 5 upper (5.2) & 254 \\
\hline Hojo Branch & Hashita, Hokuei Town & Tottori Pref. & N35.4793 & E133.8217 & 6 lower (5.8) & 275 \\
\hline Daiei Branch & Yurashuku, Hokuei Town & Tottori Pref. & N35.4902 & E133.7582 & 5 upper (5.4) & 646 \\
\hline Takatsuji & & Tottori Univ. & N35.4582 & E133.9169 & 5 upper (5.4) & 391 \\
\hline
\end{tabular}

and Togo and Hojo branches, while seismic intensity values of 5.8 are common at the three sites. However, the PGAs at the sites significantly differed, ranging from $\sim 0.3$ to $1.4 \mathrm{G}$. The ground motion records of the three sites are shown in Fig. 2. The larger horizontal component is plotted for each site. The observed acceleration after offset correction, and integrated velocity and displacement traces in the frequency domain after $0.1 \mathrm{~Hz}$ high-pass filtering are plotted in the left panel. No low-pass filter was adopted. The pseudo-velocity response spectrum with $5 \%$ damping is shown in the right panel with absolute acceleration and pseudo-displacement response axes. As indicated by the response spectrum, the predominant periods and the spectral shapes at the three sites differ. The peak period at the Kurayoshi City Office, located at the foot of the mountain, was around $0.4 \mathrm{~s}$, with a shorter second peak of $\sim 0.2 \mathrm{~s}$; that at the Hojo Site was $\sim 1.5 \mathrm{~s}$ with a steep peak. Ground motions of 0.6 and $1.4 \mathrm{~s}$ were dominant at the Togo Site. These are the key factors that caused the different PGAs at the three sites, despite the fact that common JMA seismic intensity values of 5.8 were observed. Figure 1 shows the predominant period distribution on the ground surface estimated from previous microtremor observations (Noguchi and Kagawa 2014). The predominant periods at the Kurayoshi, Hojo, and Togo sites (Fig. 1) are 0.4, 0.5, and 0.7, respectively. The predominant periods of the main shock and microtremor harmonized at the Kurayoshi City Office. However, the predominant period of the main shock is slightly longer than that of the microtremor at the Togo Site. The peak period of the main shock is much longer than that of the microtremor at the Hojo Site. However, it is not enough to make minute discussion about the discrepancy at present stage, because the observation points of the preliminary microtremor survey were spread wider around the Hojo site than other two sites.

The damage around the Kurayoshi Site, such as falling ridge roof tiles, crashing clay walls, and tumbling tombstones, suggests strong effects of the ground motion with dominant short periods. However, complete collapse of buildings was not observed in the area because the ground motions of $\sim 1-2 \mathrm{~s}$ affecting building collapse (Kawase 1998) are not large enough (Fig. 2a). Japanese wooden houses generally have a natural period of $\sim 0.3-0.5 \mathrm{~s}$; they suffered resonance between ground motions and housing vibrations and therefore were slightly damaged. The damage extended the natural period of the house and further resonance promoted further damage if the ground motions had enough power in the new natural period range. The first resonance in Kurayoshi City occurred during the period of $\sim 0.4 \mathrm{~s}$; however, further resonance did not occur because the ground motions did not have enough power in the longer period range. Therefore, much damage was observed in the Kurayoshi area; however, the damage was not severe. In the area between the Hojo and Daiei sites, several aged and low earthquakeresistant houses completely collapsed. As shown in the response spectrum in Fig. 2c, the ground motion in the period range lower than $0.5 \mathrm{~s}$ that is close to the natural period of wooden houses was not large at the Hojo Site; however, the higher peak of $\sim 1.5 \mathrm{~s}$ is suggested to affect the resonance of old houses. In general, robust wooden houses were not damaged in this area because no first resonance occurred between the ground motion and natural period of the houses.

The authors installed a strong ground motion observation site at Takatsuji, Yurihama Town, in October 2015 (Fig. 1) because seismic swarms with a maximum JMA magnitude of 4.3 had occurred in this area. Fortunately, strong motion records of the main shock and many small events were obtained at this site. A brief explanation of the site is given in Table 1; the data observed at this site were provided by Tottori University (CRMSE 2016).

As demonstrated above, strong effect of surface geology on ground motion is suggested in the area based on the peak period during the main shock of the 2016 Central Tottori Earthquake. It is important to prepare a predominant period distribution map for seismic zonation; however, the predominant periods estimated from microtremor observations do not agree with those based on strong ground motion at soft sediment sites. 

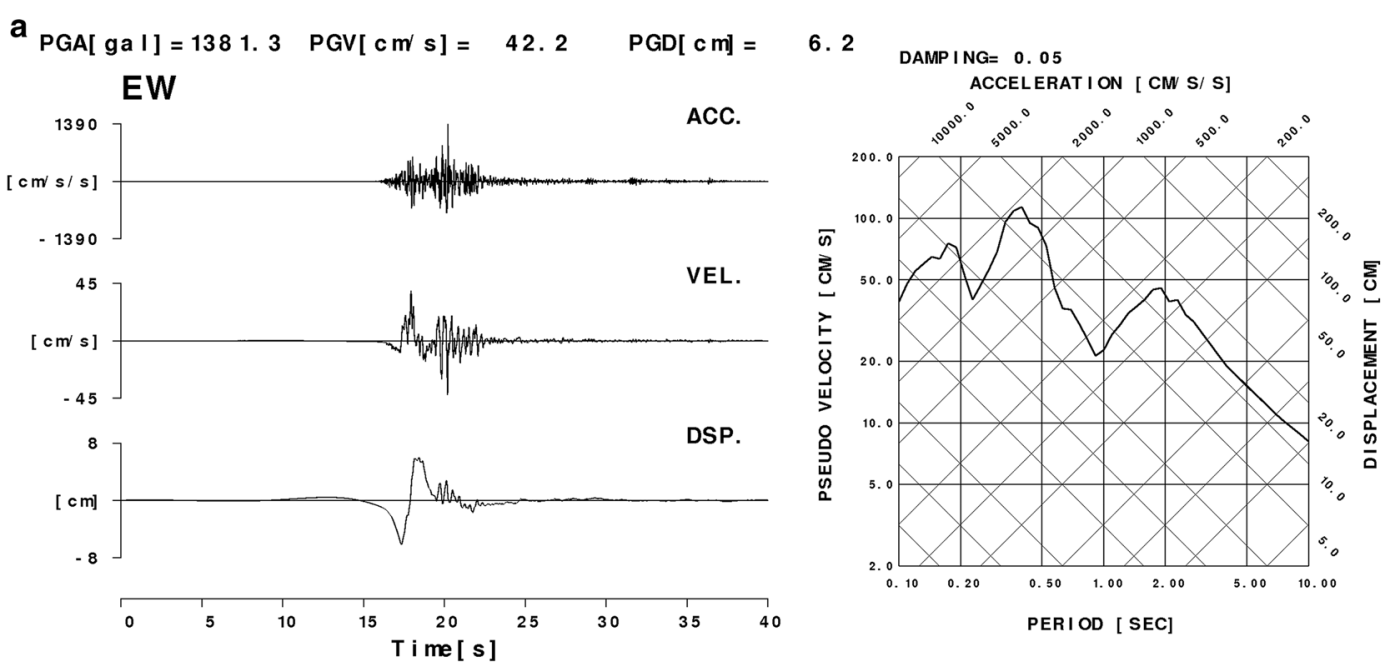

b

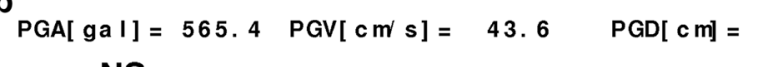

NS
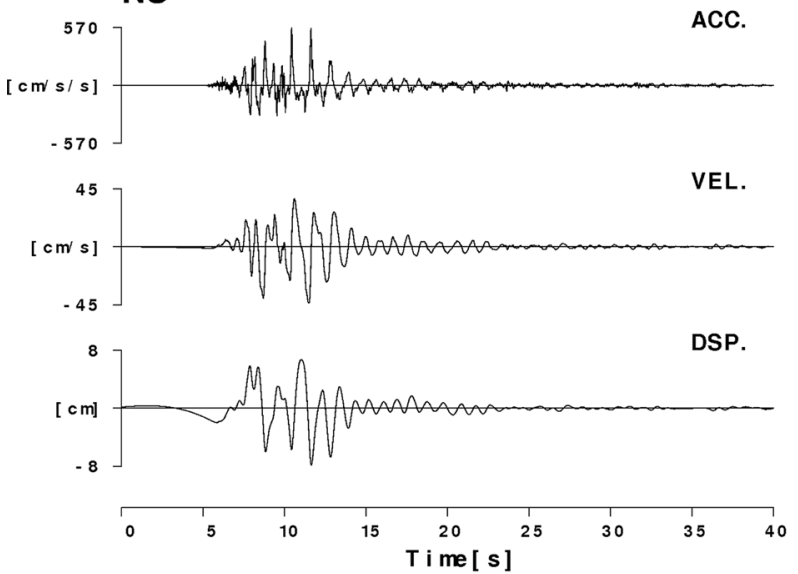

$$
\text { C. }
$$

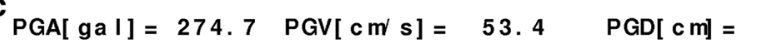

NS

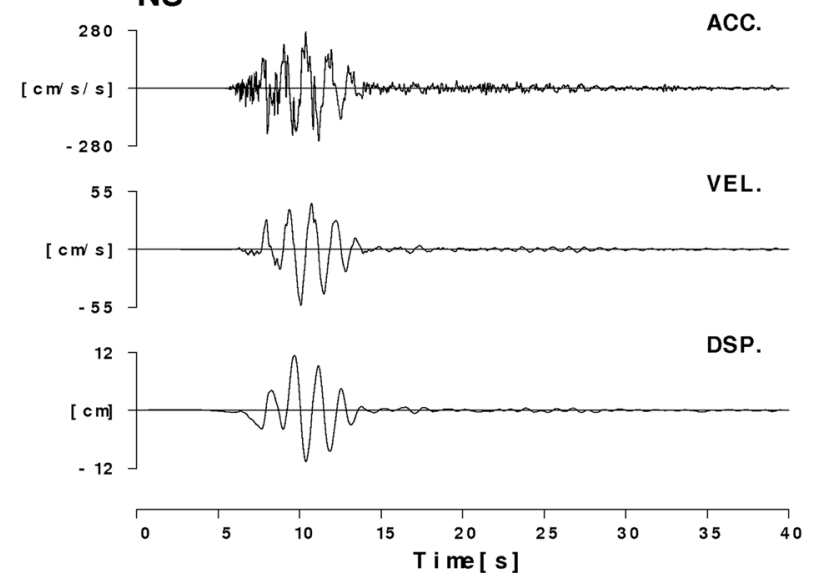

\section{9 DAMPING $=0.05$ TPF63116102114.072}

ACCELERAT I ON [ CM S/ S]

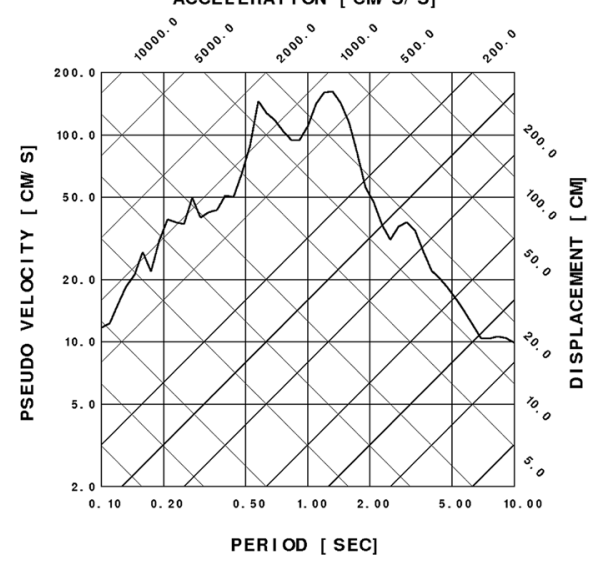

TPF66116102114. 072

11. 4 DAMP ING $=0.05$

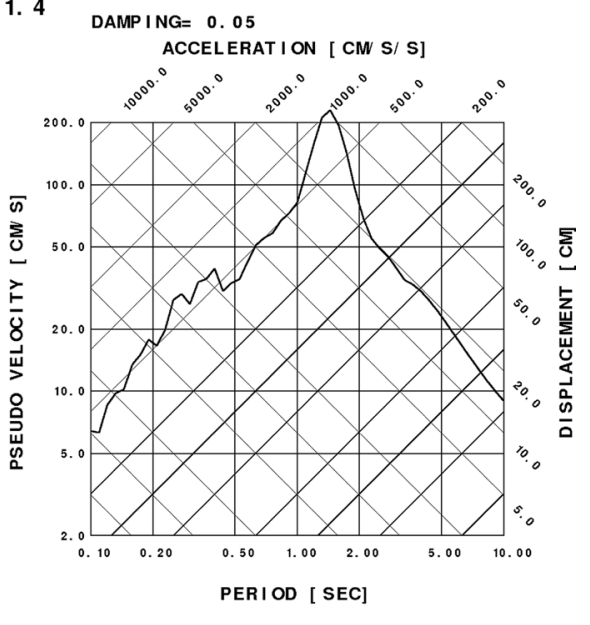

Fig. 2 Observed ground motions at the a Kurayoshi City Office, b Togo Site (Ryuto, Yurihama Town), and c Hojo Site (Hashita, Hokuei Town), with a common JMA seismic intensity of 5.8 (6 lower). The acceleration, integrated velocity, and displacement traces of the larger horizontal component observed at each site are shown in the left-hand panels; the pseudo-velocity response spectrum with $5 \%$ damping is plotted with absolute acceleration and pseudo-displacement response axes in the right-hand panels 


\section{Suspected nonlinear behavior at the Togo and Hojo sites}

Anomalous ground motion was observed in the NS component at the Togo Site (Fig. 2b). The site is located on reclaimed land close to a pond shore (Fig. 1). The original accelerogram in the figure shows pulsating swings. The amplitudes of pulses to the north are larger than those to the south. In addition, the pulses indicate rather cyclic mobility behavior, which usually is observed for liquefied ground during earthquakes (e.g., Iai et al. 1995). Despite the shape of the accelerogram, liquefactions and resulting sand boils were not identified at and around the site. However, ground subsidence of $\sim 20 \mathrm{~cm}$ was observed close to the sensor and its hood in a tree garden near the building of the town office (CRMSE 2016). Land subsidence was widely observed in and around the office. The JMA checked the setting of the accelerometer at the site shortly after the main shock because large ground motion with JMA seismic intensity of 6 lower was observed at the site. However, no issues with respect to sensor leveling or anchoring were reported.

To verify the nonlinear site response at the site under main shock, the alternation of the site response was examined using the main shock and small event records before and after the main shock. Figure 3 shows the original three-component acceleration waveforms and estimated H/V spectra of three stages (foreshock, main shock, and aftershock) after applying $0.1 \mathrm{~Hz}$ Parzen windows. The H/V spectrum derived from seismic ground motion records can be treated as site response based on diffuse wave field theory (Sánchez-Sesma et al. 2008; Kawase et al. 2011), represented by the spectral ratio of the layered structure (Haskell 1953) between S and P plane wave incidents, assuming a horizontally layered structure. The first stage (Fig. 4a) is the site response to the foreshock that occurred approximately $2 \mathrm{~h}$ before the main shock. The second stage (Fig. 4b) is the main shock with $565 \mathrm{~cm} / \mathrm{s}^{2}$ peak horizontal acceleration. The longest peak period of $\sim 1.5 \mathrm{~s}$ corresponds to the

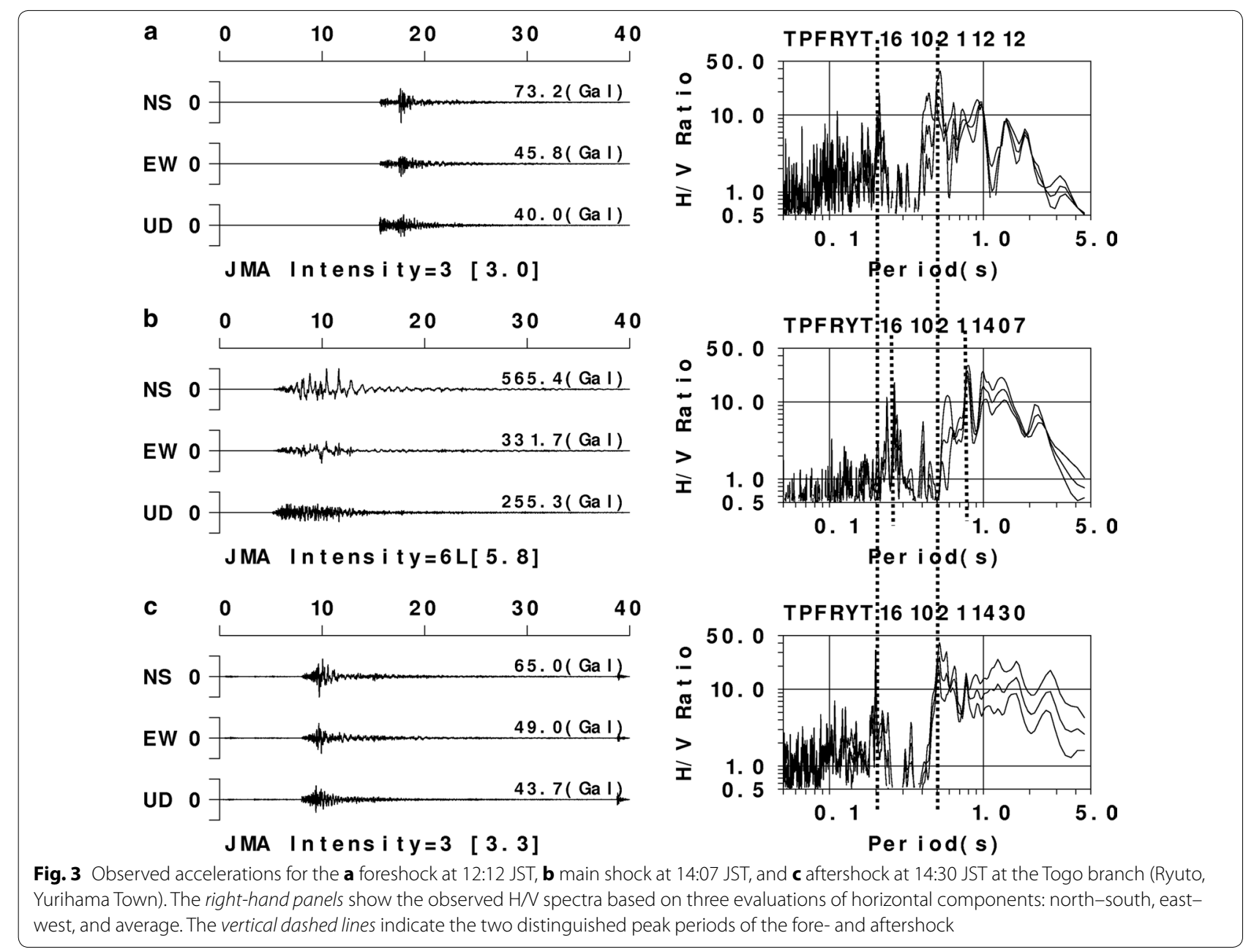



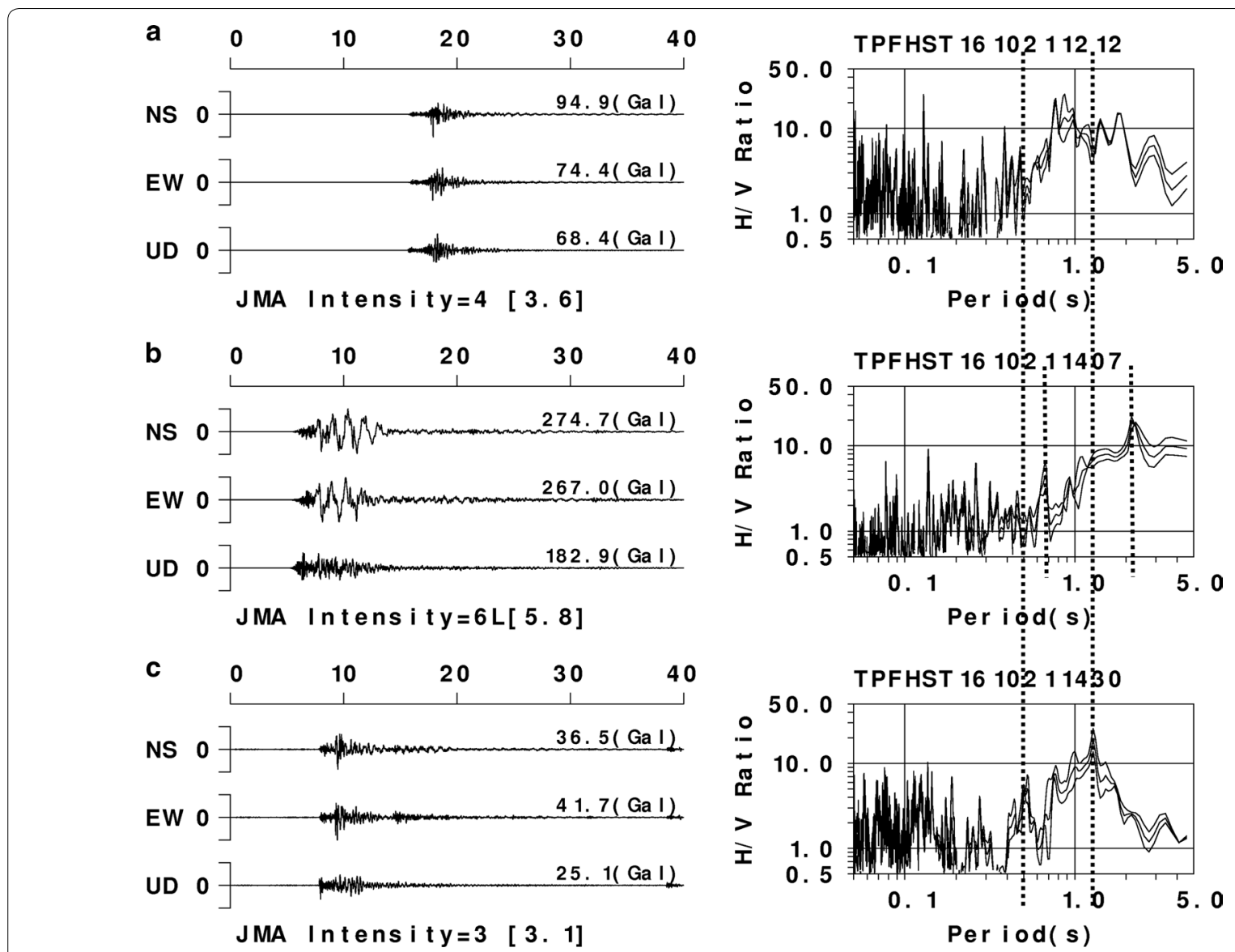

Fig. 4 Observed accelerations for the a foreshock at 12:12 JST, b main shock at 14:07 JST, and c aftershock at 14:30 JST at the Hojo branch (Hashita, Hokuei Town). Details are same as Fig. 3

predominant period in Fig. 2b. The third stage (Fig. 4c) is the site response to the aftershock that occurred approximately 20 min after the main shock. Unfortunately, this is the first recorded aftershock event at this site because the observation systems maintained by the Tottori Prefecture stored only triggered records. The distinguished peak periods commonly recognized in small event data are indicated as dashed lines in Fig. 3. However, the corresponding peaks of the main shock data are shifted to longer periods, for example, from 0.2 to $0.25 \mathrm{~s}$ or from 0.5 to $0.8 \mathrm{~s}$. The $\sim 1.6$ times shift of the predominant period of the latter case corresponds to a change in the shear wave velocity of approximately $1 / 1.6$, assuming that the thickness of the soft surface layer does not change. Hence, the reduction in the rigidity is roughly 0.4 and the strain level is $\sim 10^{-3}$ considering the general behavior of sand soil used in equivalent linear analyses. These results suggest high nonlinearity; however, it is not large enough to produce liquefaction. The soil behavior during the main shock at the site has to be studied; it is suggested that the stiffness of the shallow soil structure of the site decreased and started to move horizontally. This led to the collision of shallow soil with the garden wall, reflected by the anomalous waveform of the accelerogram of the NS component.

The same analysis was conducted at the Hojo Site (Fig. 2c). The results are shown in Fig. 4. The predominant period of $1.5 \mathrm{~s}$ in Fig. $2 \mathrm{c}$ is not clear in Fig. 4b; the longest peak estimated from the strong motion $\mathrm{H} / \mathrm{V}$ spectral ratio is $\sim 2.2 \mathrm{~s}$. The peaks observed for the small event (dashed lines) shift to longer periods during the main shock. The changes are estimated as $0.5-0.7 \mathrm{~s}$ and 1.2-2.2 s (Fig. 4), respectively. The estimated rigidity reduction is $\sim 0.3$, suggesting a larger strain level than that at the Togo Site. No liquefaction or ground deformation was observed around the site.

For both sites, the peak period during stage 3 (aftershock) agrees well with that of stage 1 (foreshock). It is suggested that the high strain level that causes the nonlinear site response recovered within $30 \mathrm{~min}$ after the main shock. Hata et al. (2017) reported the recovery of shear wave velocities in Mashiki Town due to the main 
shock of the 2016 Kumamoto Earthquake. Based on their observations, the high strain level recovered $1000 \mathrm{~h}$ after the main shock. This is much longer than our result of 30 min, which might be due to the local soil profile suffering from ground motions.

The nonlinear site response suggests that the estimation of the predominant period distribution from microtremor observations is not enough to induce microzonation under strong ground motions. The predominant period might be longer, particularly at soft sediment sites. Such effects were observed during the 2016 Kumamoto Earthquake (Goto et al. 2017). Nonlinear site responses should be considered with respect to seismic microzonation in the future.

\section{Summary and conclusions}

The spectral properties of strong ground motions observed during the 2016 Central Tottori Earthquake with a JMA magnitude of 6.6 were examined with respect to predominant periods from preliminary microtremor observations at the observation sites. The following results were obtained:

1. A JMA seismic intensity of 6 lower was observed at three sites: Kurayoshi, Hojo, and Togo. The intensity values were 5.8 at all sites; however, the PGAs varied between 0.3 and $1.4 \mathrm{G}$.

2. The PGA values were affected by distinguished periods of observed ground motions; they were basically controlled by predominant periods of the ground surface estimated from previous microtremor observations.

3. It is true for the hard site Kurayoshi; however, the predominant periods of the main shock were longer than those of microtremors at the soft sites Hojo and Togo.

4. Nonlinear site responses were suggested for soft sites. The distinguished periods of the main shock record shifted to longer periods than those of the weak motion data. A stiffness decrease due to the nonlinear site effect was estimated for each site.

5. Predominant periods estimated from microtremor observations are not sufficient for disaster mitigation of soft sites. The consideration of nonlinear site responses might be the key for future seismic microzonation studies.

Based on records of the strong ground motion due to the earthquake, the ground motion characteristics from previous surveys were reconfirmed for the target area. In the future, we would like to carefully examine the effect of the surface geology using aftershock records at temporal sites around permanent observatories that were installed shortly after the main shock and the dense microtremor observation data obtained at strong ground motion observation sites. In addition, the nonlinear site response in the target area needs to be estimated.

\section{Data and resources}

Strong motion data obtained at the Kurayoshi City Office Site (K-NET TTR005) are available from the National Research Institute for Earth Science and Disaster Resilience (NIED) at http://www.kyoshin.bosai. go.jp (last accessed February 2017). The main shock data of the Takatsuji Site can be obtained from the Center for Regional Management and Safety Engineering (CRMSE), Faculty of Engineering, Tottori University, at http://www. eng.tottori-u.ac.jp/anzen/takatsuji.csv (last accessed February 2017). The main shock data for other sites maintained by the Tottori Prefecture are provided by the Japan Meteorological Agency (JMA) at http://www.data.jma. go.jp/svd/eqev/data/kyoshin/jishin/1610211407_tottoriken-chubu/index.html (last accessed February 2017, in Japanese).

\section{Authors' contributions}

TK, TN, SYo, and SYa conducted the microtremor observations and TN integrated the results. SYa maintained the strong motions site at Takatsuji. SYo carried out the basic analysis of strong ground motion records. TK drafted the manuscript after discussions among all authors. All authors read and approved the final manuscript.

\section{Author details \\ ${ }^{1}$ Graduate School of Engineering, Tottori University, 4-101 Koyama- cho-Minami, Tottori, Japan. ${ }^{2}$ Technical Department, Tottori University, 4-101} Koyamacho-Minami, Tottori, Japan.

\section{Acknowledgements}

The authors thank the Crisis Management Bureau of the Tottori Prefecture for providing small event data obtained at the Togo Site.

\section{Competing interests}

The authors declare that they have no competing interests.

\section{Funding}

This study was partially supported by a Grant-in-Aid for Scientific Research, KAKENHI, from the Japan Society for the Promotion of Science (Grant No. 15K01250) and Observation and Research Program for the Prediction of Earthquakes and Volcanic Eruptions, Subdivision on Geodesy and Geophysics, Council for Science and Technology of the Ministry of Education, Culture, Sports, Science, and Technology (MEXT).

\section{Ethics in human and animal research}

The authors declare that this article does not contain any studies of human and animal subjects.

\section{Publisher's Note}

Springer Nature remains neutral with regard to jurisdictional claims in published maps and institutional affiliations.

Received: 28 February 2017 Accepted: 31 July 2017

Published online: 15 August 2017 


\section{References}

Aoi S, Kunugi T, Fujiwara H (2004) Strong motion seismograph network operated by NIED: K-NET and KiK-net. J Jpn Assoc Earthq Eng 4(3 (Special Issue)):65-74

Center for Regional Management and Safety Engineering (CRMSE), Faculty of Engineering, Tottori University (2016) Phenomenon analysis of the 2016 Central Tottori Earthquake. http://www.eng.tottori-u.ac.jp/anzen/ eq2016a.html. Accessed Feb 2017 (in Japanese)

Earthquake Research Committee, Headquarters for Earthquake Research Promotion (HERP) (2016) Evaluation of the earthquake in the Central Tottori Prefecture on October 21, 2016. http://www.jishin.go.jp/main/index-e. html. Accessed Feb 2017

Geospatial Information Authority of Japan (GSI) (2016) The 2016 Central Tottori Earthquake. http://www.gsi.go.jp/cais/topic161027-index-e.html. Accessed Feb 2017

Goto H, Hata Y, Yoshimi M, Yoshida N (2017) Nonlinear site response at KiK-net KMMH16 (Mashiki) and heavily damaged sites during the 2016 Kumamoto Earthquake (Mw7.1), Japan. Bull Seismol Soc Am. doi:10.1785/0120160312

Haskell NA (1953) The dispersion of surface waves on multilayered media. Bull Seismol Soc Am 43(1):17-34

Hata Y, Yoshimi M, Goto H, Hosoya T, Morikawa H, Kagawa T (2017) Recovery process of shear wave velocities of volcanic soil in central Mashiki Town after the 2016 Kumamoto earthquake revealed by intermittent measurements of microtremor. Earth Planets Space. doi:10.1186/ s40623-017-0657-8 lai S, Morita T, Kameoka T, Matsunaga Y, Abiko K (1995) Response of a dense sand deposit during 1993 Kushiro-Oki Earthquake. Soils Found 35(1):115-131

Kawase $H$ (1998) Metamorphosis of near-field strong motions by underground structures and their destructiveness to man-made structures, learned from the damage belt formation during the Hyogo-ken Nanbu Earthquake of 1995. In: Proceedings of the 10th Japan earthquake engineering symposium 10:29-34 (in Japanese)

Kawase H, Sánchez-Sesma FJ, Matsushima S (2011) The optimal use of horizontal-to-vertical spectral ratios of earthquake motions for velocity inversions based on diffuse-field theory for plane waves. Bull Seismol Soc Am 101(5):2001-2014. doi:10.1785/0120160312

National Research Institute for Earth Science and Disaster Resilience (NIED) (2016) K-NET\&KiK-net preliminary report, 2016/10/21-14:07:00.00 35.38 N 133.85E 011 km M6.6, http://www.kyoshin.bosai.go.jp/cgi-bin/kyoshin/ bigeqs/index.cgi?E. Accessed Feb 2017

Nishimae Y (2004) Observation of seismic intensity and strong ground motion by Japan Meteorological Agency and local governments in Japan. J J.pn Assoc Earthq Eng 4(3 (Special Issue)):75-78

Noguchi T, Kagawa T (2014) Determination of subsurface structure of the seaside area of Kurayoshi plain, Tottori Prefecture, by microtremor and gravity exploration. J Jpn Soc Civil Eng Ser A1 (Struct Eng Earthq Eng SE/ EE) 70(4):I_888-I_896 (in Japanese with English abstract)

Sánchez-Sesma FJ, Pérez-Ruiz JA, Luzón F, Campillo M, Rodríguez-Castellanos A (2008) Diffuse fields in dynamic elasticity. Wave Motion 45:641-654

\section{Submit your manuscript to a SpringerOpen ${ }^{\circ}$ journal and benefit from:}

- Convenient online submission

- Rigorous peer review

- Open access: articles freely available online

- High visibility within the field

- Retaining the copyright to your article

Submit your next manuscript at $>$ springeropen.com 